\title{
Aguardente de jabuticaba obtida da casca e borra da fabricação de fermentado de jabuticaba
}

\author{
Jabuticaba fruit aguardiente made from skin and \\ sediments resulting from the production of fermented jabuticaba
}

Eduardo Ramirez ASQUIERI ${ }^{1 *}$, Aline Gomes de Moura e SILVA ${ }^{1}$, Marcos Antônio CÂNDIDO² $^{2}$

\section{Resumo}

Este trabalho teve como objetivo produzir aguardente de jabuticaba a partir do subproduto da fabricação do fermentado de jabuticaba (casca e borra) e verificar a sua qualidade mediante análises físico-químicas e posterior comparação aos padrões de aguardente de frutas existentes na legislação brasileira. O teor de ésteres $\left(357 \mathrm{mg} .100 \mathrm{~mL}^{-1}\right)$ apresentou-se acima do estipulado pela legislação $(250 \mathrm{mg} .100 \mathrm{~mL}$-1) e em relação a outras aguardentes de frutas também foi elevado. Com respeito às outras variáveis, não foram encontrados valores discrepantes como, por exemplo, valores de grau alcoólico $\left(39^{\circ} \mathrm{GL}\right)$, densidade $\left(0,95 \mathrm{~cm}^{3} \cdot \mathrm{g}^{-1}\right)$, acidez volátil $\left(30 \mathrm{mg} \cdot 100 \mathrm{~mL}^{-1}\right)$. Assim sendo, a aguardente é uma alternativa para produtores rurais que cultivam a jabuticaba evitando perdas pós-colheita consideráveis durante a safra.

Palavras-chave: Myrciaria jabuticaba Berg; aguardente de frutas; bebidas fermentadas.

\begin{abstract}
This study aimed at producing jabuticaba rum by using the byproduct of the production of the wine of jabuticaba (skin and pulp) and assessing its quality through physicochemical analysis and comparing it to the patterns established by the Brazilian legislation regarding the production of fruit rum. The total ester index (357 mg.100 mL $\left.\mathrm{mL}^{-1}\right)$ was above the one established by the Brazilian law $\left(250 \mathrm{mg} .100 \mathrm{~mL}^{-1}\right)$, and it was also high if compared to other fruit rums. As to other variables, such as alcoholic degree values $\left(39^{\circ} \mathrm{GL}\right)$, density $\left(0,95 \mathrm{~cm}^{3} \cdot \mathrm{g}^{-1}\right)$, volatile acidity (30 mg.100 $\mathrm{mL}^{-1}$ ) no discrepancy, was found. Thus, the jabuticaba rum is an alternative for producers since it prevents post-harvesting losses. Keywords: Myrciaria jabuticaba Berg; fruit aguardientes; fermented beverages.
\end{abstract}

\section{Introdução}

A jabuticaba é originária do centro-sul do Brasil e, dentre as espécies atualmente conhecidas, destacam-se a Myrciaria cauliflora (DC) Berg e a Myrciaria jabuticaba (Vell) Berg que produzem frutos apropriados tanto para consumo in natura quanto para a indústria. A jabuticabeira é uma árvore de tamanho médio, cujas folhas são lanceoladas, as flores são brancas e os frutos globosos (Figura 1). A casca dos frutos maduros é preta, sendo fina e frágil, com a polpa branca, ligeiramente ácida e doce. A jabuticabeira é uma frutífera de grande interesse para os produtores rurais de diversas regiões brasileiras, devido à sua alta produtividade, rusticidade e aproveitamento dos frutos das mais diversas formas. Com a jabuticaba podem-se produzir sucos, fermentado, geleia, compotas, licor e vinagre (ANDERSEN, 1989; BRUNINI et al., 2004).

A utilização de sucos de frutas para elaboração de bebidas alcoólicas é uma forma de aproveitamento com o intuito de evitar o desperdício quando não se tem um consumo imediato, também agregando valor às bebidas regionais. Na Amazônia e nos Andes, a caiçuma e chicha, cujas matérias-primas são: a pupunha e o milho (ou mandioca), respectivamente, são bebidas alcoólicas fermentadas geralmente consumidas em ocasiões comemorativas (ANDRADE; PANTOJA; MAEDA, 2003).

São vários os estudos divulgados sobre a preparação e caracterização de fermentados de frutas, podem ser citados o de cajá (DIAS; SCHWAN; LIMA, 2003), ata, ciriguela, mangaba (MUNIZ et al., 2002), caju (TORRES NETO et al., 2006), laranja (CORAZZA; RODRIGUES; NOZAKI, 2001) e jabuticaba (ASQUIERI et al., 2004a).

A partir dos fermentados de frutas, por meio de destilação se obtêm as aguardentes de frutas sendo necessária à adaptação do processo de produção de acordo com a matéria-prima. O Decreto $\mathrm{n}^{\circ} 2314$ define aguardente de frutas ou brandy de frutas como a bebida de graduação alcoólica de 36 a $54{ }^{\circ} \mathrm{GL}$, a $20^{\circ} \mathrm{C}$, obtida de destilado alcoólico simples de fruta, ou pela destilação de mosto fermentado de fruta (BRASIL, 1997). Neste caso, podem-se citar alguns exemplos como aguardente de manga (ALVARENGA; MAIA; OLIVEIRA, 2006), de mexerica (MUNHOZ et al., 2006) e de abacaxi (SILVA JÚNIOR et al., 2006).

Recebido para publicação em 21/2/2008

Aceito para publicação em 5/1/ 2009 (003251)

${ }^{1}$ Faculdade de Farmácia, Universidade Federal de Goiás - UFG, CEP 74605-220, Goiânia - GO, E-mail: asquieri@farmacia.ufg.br

${ }^{2}$ Instituto Médico Legal, Goiânia - GO

${ }^{*}$ A quem a correspondência deve ser enviada 
Também segundo o Decreto ${ }^{\circ} 2314$ (BRASIL, 1997) e Aquarone et al. (2001), as aguardentes de frutas podem apresentar denominações diferenciadas como a aguardente de cereja, chamada de kirsch ou cherry brandy; a aguardente de ameixa, como slivowicz ou mirabella; a aguardente de pêra, como pear brandy; a aguardente de pêssego, como peach brandy; e a aguardente de maçã, como apple brandy.

Pesquisas foram realizadas modificando-se o processo fermentativo e variando os substratos para verificar o impacto na composição e rendimento das aguardentes. Em estudo, Cleto e Mutton (2004) constataram que o uso de lecitina no processo fermentativo de aguardentes de cana, uva e laranja diminuiu o rendimento alcoólico; Silva et al. (2004), ao produzirem aguardente a partir da casca, da polpa e da banana prata integral, concluíram que apenas aquelas obtidas da polpa e da banana integral apresentaram boa qualidade físico-química. Já Briones, Hernández-Gómez e Ubeda (2002) que, para produção de aguardente de melão, utilizaram como matérias-primas o melão inteiro, a polpa e semente e somente a polpa, afirmam que os rendimentos são muito baixos e é preciso melhorá-los.

Para diferenciar o produto, uma alternativa é aromatizá-lo com cascas de frutas, como casca de tangerina e laranja, que conferem cor à bebida (ALVAREZ et al., 2004). Estas modificações devem estar aliadas às análises químicas e sensoriais, pois nem sempre uma mudança no processo tecnológico resultará em um produto final satisfatório.

Este trabalho teve como objetivo produzir aguardente de jabuticaba a partir do subproduto da fabricação do fermentado de jabuticaba e verificar a sua qualidade mediante análises físico-químicas e posterior comparação aos padrões de aguardente de frutas existentes na legislação brasileira.

\section{Material e métodos}

A matéria-prima foi o subproduto obtido da produção de fermentado de jabuticaba (casca e borra) cedida pela Vinícola Jabuticabal de Hidrolândia - GO. A aguardente de jabuticaba

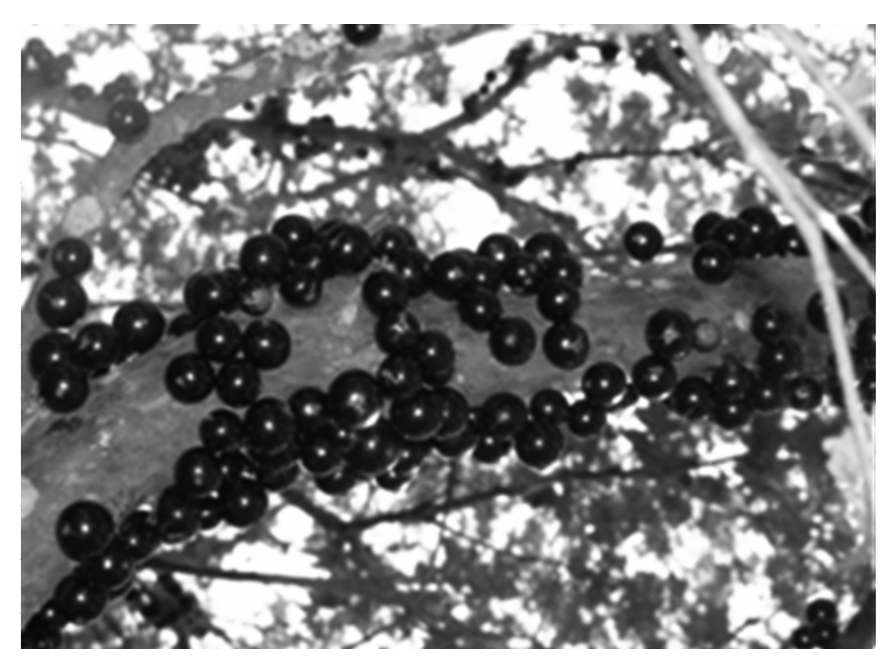

Figura 1. Jabuticaba (Myrciaria jabuticaba Berg). foi desenvolvida no Laboratório de Química e Bioquímica de Alimentos da Faculdade de Farmácia, Universidade Federal de Goiás, em técnica de micro processo e logo transferida à indústria em escala piloto.

\subsection{Análises físico-químicas}

As análises da aguardente de jabuticaba após 6 meses de armazenamento foram realizadas em triplicata.

- Densidade: Para sua determinação foi utilizado o método do picnômetro (VOGT, 1972).

- $\mathrm{pH}$ : Foi determinado através de pHmetro Analion, modelo PM 608, com amostra isenta de álcool. Para retirada do álcool, colocou-se $50 \mathrm{~mL}$ da amostra (medida em balão volumétrico) em béquer, para que em banho-maria fervente houvesse uma redução de 50\%. Em seguida, o volume inicial foi completado com água destilada e fez-se a medição do pH (AMERINE; OUGH, 1976).

- Açúcares redutores e sacarose: Os açúcares redutores da amostra desalcoolizada foram determinados pelo método do ácido 3-5 dinitrossalicílico (MILLER, 1959). A análise de sacarose foi realizada conforme o método ADNS adaptado (SILVA et al., 2003).

- Grau alcoólico: Determinou-se com uso de alcoômetro de Gay-Lussac colocado diretamente em volume de $250 \mathrm{~mL}$ de destilado a $20^{\circ} \mathrm{C}$ (IAL, 1985).

- Acidez total: Determinou-se por titulação da amostra com $\mathrm{NaOH}$ 0,1N, utilizando-se fenolftaleína como indicador (BRASIL, 2005).

- Ácidos voláteis: Após a destilação da amostra, fez-se a correção do destilado para $50^{\circ} \mathrm{GL}$ e titulou-se com $\mathrm{NaOH}$ 0,1N (IAL, 1985).

- Ésteres: Utilizou-se a amostra da determinação de ácidos voláteis, titulando-se o excesso de ácido sulfúrico com $\mathrm{NaOH}$ 0,1N (IAL, 1985).

- Acidez fixa: Foi determinada pela diferença entre a acidez total e a volátil (IAL, 1985).

- Proteína: Pelo método de Biureto foi quantificado o teor de proteína na amostra desalcoolizada (VILELA; BACILA; TASTALDI, 1973).

- Taninos: Foram quantificados por espectrofotometria com reagente de Folin-Denis, utilizando-se a amostra desalcoolizada (CANECHIO FILHO, 1972).

- Dióxido de enxofre livre e total: Baseia-se no desprendimento do dióxido de enxofre livre em presença de ácido sulfúrico, titulando-o com solução de iodo. Para determinar o dióxido de enxofre total, utiliza-se uma base forte (hidróxido de sódio), depois se acidifica (ácido sulfúrico) e titula-se com solução de iodo (AMERINE; OUGH, 1976).

- Extrato seco: Determinou-se por meio da evaporação em estufa a $105^{\circ} \mathrm{C}$ até peso constante (IAL, 1985). 
- Análise de minerais: Foram realizadas na amostra desalcoolizada, análise de ferro pelo método de Goodwin modificado, cálcio pelo método CPC, magnésio pelo método Labtest e fosfato pelo método Gomori modificado (LABTEST, 1995), cobre, utilizando-se equipamento de absorção atômica Varian AA 200 (BRASIL, 2005).

- Cinzas: Foram determinadas após calcinação da amostra a $550^{\circ} \mathrm{C}$ até peso constante (IAL, 1985).

- Análise de furfural, metanol, aldeídos, álcoois n-propílico, n-butílico, iso-butílico, iso-amílico, sec-butílico: foram determinados por cromatografia gasosa utilizando-se cromatógrafo GC-17A Shimadzu, injetor automático AOC-20i Shimadzu, detector FID e coluna CPWAX 57CB, $50 \mathrm{~m} \times 0,22 \mathrm{~mm}$ e espessura de $0,2 \mu \mathrm{m}$ marca Chrompack (BRASIL, 2005).

\section{Processo tecnológico da fabricação de aguardente de jabuticaba}

A aguardente de jabuticaba foi produzida utilizando o subproduto (casca e borra) da fabricação do fermentado de jabuticaba. Para sua produção, como indicado na Figura 2, foram utilizadas jabuticabas da espécie Myrciaria jabuticaba Berg que, após serem selecionadas e lavadas, foram esmagadas e o suco foi colocado em tanques de aço inox com capacidade de $500 \mathrm{~L}$.

O suco de jabuticaba obteve entre 18 a $22^{\circ} \mathrm{Brix}$, excelente para sua fermentação (ASQUIERI et al., 2004a). Foram acrescentados $2 \%$ de metabissulfito de sódio com a finalidade de selecionar as leveduras próprias para fermentação e eliminar as indesejáveis. $\mathrm{O}$ processo fermentativo ocorreu durante cinco dias, a $\mathrm{pH}$ entre 3,0 e 3,5 e a uma temperatura de $25 \mathrm{a} 35^{\circ} \mathrm{C}$. Este processo foi realizado por leveduras selvagens até atingir $0{ }^{\circ}$ Brix e grau alcoólico de $11^{\circ} \mathrm{GL}$. Por bombeamento, retirou-se o líquido fermentado para a produção do fermentado de jabuticaba.

As cascas foram separadas e prensadas em prensa hidráulica. O líquido resultante, juntamente com os resíduos dos tanques de maturação (borra) de fermentado de jabuticaba, foi armazenado em tambores de plástico de 200 L para aguardar a destilação. Esta etapa (destilação) foi realizada em alambique de cobre, com capacidade de $100 \mathrm{~L}$ e sistema de aquecimento direto, como é apresentado na Figura 3.

Após a lavagem do alambique, este foi carregado com $20 \mathrm{~L}$ de caldo. Na primeira etapa da destilação foram recolhidos $10 \%$ da cabeça do destilado, que foram descartados ou destinados a outros usos. O coração foi recolhido a partir de um grau alcoólico de $52{ }^{\circ} \mathrm{GL}$ até atingir $27^{\circ} \mathrm{GL}$, que equivale a aproximadamente $60 \%$ do destilado, ficando, desta maneira, $30 \%$ de cauda e vinhoto, que foram descartados.

A fração coração foi levada para barris de carvalho para maturação durante seis meses (Figura 4).

O engarrafamento da aguardente de jabuticaba foi realizado em equipamento manual com capacidade de 150 garrafas/hora. As garrafas foram armazenadas por um período de 6 meses antes de serem analisadas (Figura 5).

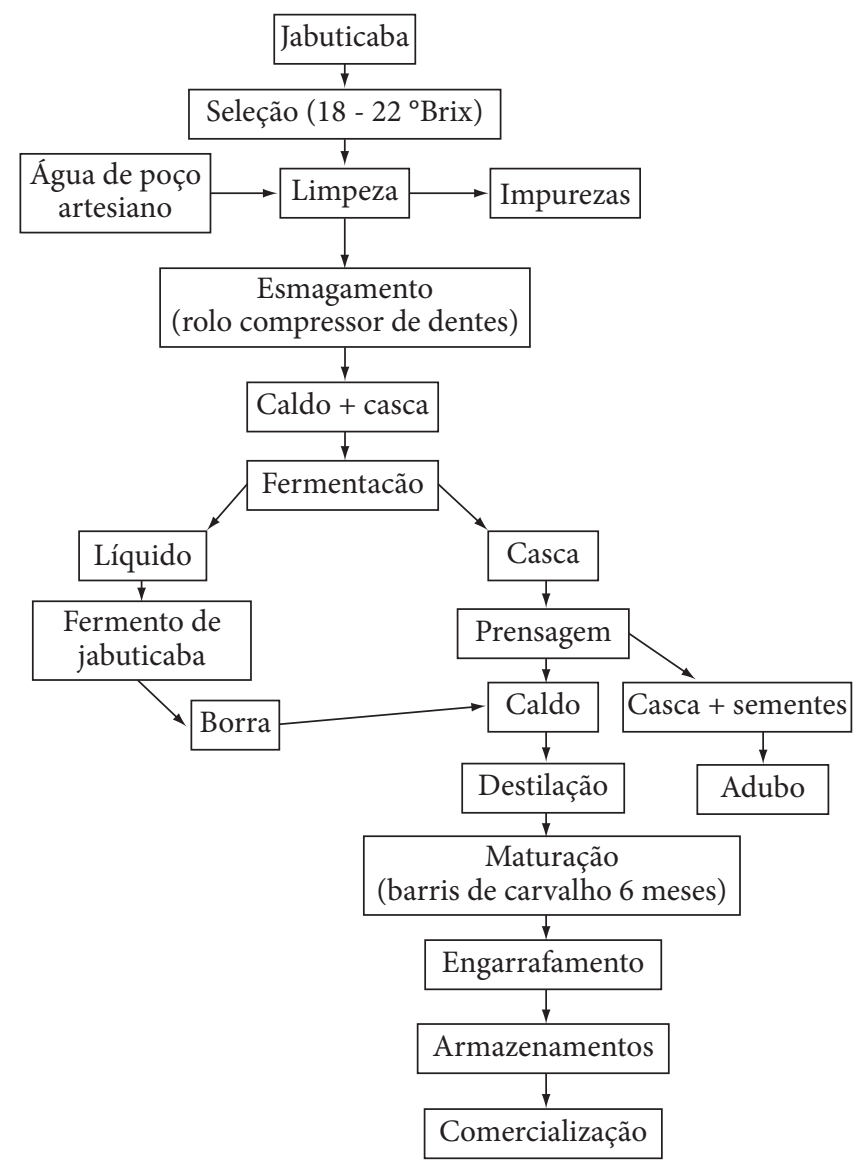

Figura 2. Diagrama de fluxo para fabricação de aguardente de jabuticaba.

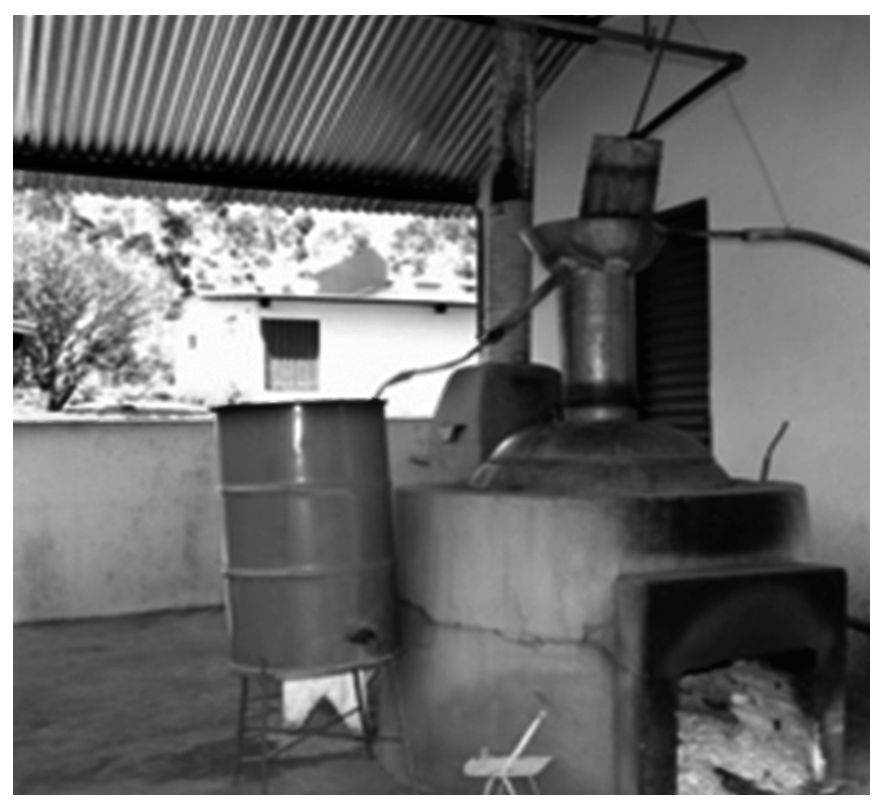

Figura 3. Alambique. 


\section{Resultados e discussão}

Os dados das análises físico-químicas para a aguardente de jabuticaba cedida pela Vinícola Jabuticabal, Nova Fátima, Goiás, Brasil, são apresentados na Tabela 1.

O Ministério da Agricultura na Portaria no 65, de 23 de abril de 2008 (BRASIL, 2008) estabelece para aguardente de frutas, valores de teor alcoólico, acidez volátil, ésteres, aldeídos, açúcares, álcoois superiores, furfural, metanol, cobre, coeficiente de congêneres conforme observado na Tabela 1, além de chumbo e ácido cianídrico.

O teor alcoólico da aguardente de jabuticaba $\left(39^{\circ} \mathrm{GL}\right)$ está dentro da faixa estabelecida pela legislação para aguardente de frutas de 36 a $54^{\circ} \mathrm{GL}$, (BRASIL, 2008). A graduação característica deste tipo de bebida é em torno de $40^{\circ} \mathrm{GL}$ (MARTÍNEZetal., 1997), confirmada pela porcentagem alcoólica de aguardentes obtidas de uva e laranja (CLETO; MUTTON, 2004), de 41,5 e 40,5\%, respectivamente, e aguardentes de cana aromatizadas com casca de tangerina e laranja (ALVAREZ et al., 2004), de 41,6 e $39,6^{\circ} \mathrm{GL}$, respectivamente. Assim como com a aguardente de polpa de banana prata com $38,3^{\circ} \mathrm{GL}$ (SILVA et al., 2004). Um valor mais elevado foi encontrado para cachaça de abacaxi, de 47\% (SILVA JÚNIOR et al., 2006).

Em relação à densidade, o valor para a aguardente de jabuticaba de $0,95 \mathrm{~cm}^{3} \cdot \mathrm{g}^{-1}$ é semelhante aos valores encontrados de $0,95 \mathrm{~cm}^{3} \cdot \mathrm{g}^{-1}$

Tabela 1. Dados analíticos da aguardente de jabuticaba e parâmetros de qualidade do Ministério da Agricultura (MAPA), segundo Portaria $\mathrm{n}^{\circ} 65$, de 23/04/2008, para aguardente de frutas.

\begin{tabular}{|c|c|c|c|}
\hline \multirow[t]{2}{*}{ Variáveis } & \multicolumn{2}{|c|}{ MAPA } & \multirow{2}{*}{$\begin{array}{l}\text { Valores } \\
\text { médios }\end{array}$} \\
\hline & Mín. & Máx. & \\
\hline Álcool em volume $\left({ }^{\circ} \mathrm{GL}\right)$ & 36,00 & 54,00 & 39,00 \\
\hline Densidade $\left(\mathrm{cm}^{3} \cdot \mathrm{g}^{-1}\right)$ & & & 0,95 \\
\hline Extrato seco (g.L $\left.\mathrm{L}^{-1}\right)$ & & & 0,11 \\
\hline Açúcares redutores e sacarose (g. $\left.\mathrm{L}^{-1}\right)$ & - & 6,00 & 0,00 \\
\hline Acidez total (mg ácido acético.100 mL m $^{-1}$ ) & & & 55,00 \\
\hline Acidez volátil (mg ácido acético. $100 \mathrm{~mL}^{-1}$ ) & - & 100,00 & 30,00 \\
\hline Acidez fixa (mg ácido acético.100 mL $\mathrm{L}^{-1}$ ) & & & 25,00 \\
\hline $\mathrm{pH}$ & & & 2,83 \\
\hline Cinzas (\%) & & & 0,005 \\
\hline Proteína (\%) & & & 0,00 \\
\hline Cálcio $\left(\mathrm{mg} \cdot \mathrm{dL}^{-1}\right)$ & & & 2,20 \\
\hline Ferro $\left(\mathrm{mg} \cdot \mathrm{dL}^{-1}\right)$ & & & 0,05 \\
\hline Magnésio (mg.dL $\left.{ }^{-1}\right)$ & & & 0,50 \\
\hline Fosfato $\left(\mathrm{mg} \cdot \mathrm{dL}^{-1}\right)$ & & & 0,20 \\
\hline Cobre $\left(m g . L^{-1}\right)$ & - & 5,00 & 0,70 \\
\hline Dióxido de enxofre total (mg.L $\left.\mathrm{L}^{-1}\right)$ & & & 5,28 \\
\hline Dióxido de enxofre livre (mg. $\left.\mathrm{L}^{-1}\right)$ & & & 3,17 \\
\hline Taninos (g.L $\left.\mathrm{L}^{-1}\right)$ & & & 0,03 \\
\hline Furfural $\left(\mathrm{mg} .100 \mathrm{~mL}^{-1}\right)$ & - & 5,00 & $\mathrm{ND}^{*}$ \\
\hline Ésteres em acetato de etila (mg.100 mL $\left.\mathrm{mL}^{-1}\right)$ & - & 250,00 & 357,00 \\
\hline Aldeídos em aldeído acético (mg.100 mL $\left.\mathrm{mL}^{-1}\right)$ & - & 30,00 & 13,60 \\
\hline Álcoois superiores $\left(\mathrm{mg} .100 \mathrm{~mL}^{-1}\right)$ & - & 360,00 & 259,07 \\
\hline Metanol (mg.100 mL $\left.{ }^{-1}\right)$ & - & 20,00 & 4,30 \\
\hline C. de congêneres (mg.100 mL $\mathrm{m}^{-1}$ ) & 200,00 & 650,00 & 659,67 \\
\hline
\end{tabular}

${ }^{*} \mathrm{ND}$ - não detectado. e de $0,947 \mathrm{~cm}^{3} \cdot \mathrm{g}^{-1}$ para aguardente de cana (BIZELLI; RIBEIRO; NOVAES, 2000; MORI et al., 2003), de $0,932 \mathrm{~cm}^{3} \cdot \mathrm{g}^{-1}$ para cachaça de abacaxi (SILVA JÚNIOR et al., 2006) e de $0,9524 \mathrm{~cm}^{3} . \mathrm{g}^{-1}$ para aguardente de polpa de banana prata (SILVA et al., 2004).

O extrato seco de destilados é constituído de substâncias como carboidratos, taninos, caramelo, ácidos fixos e por componentes minerais extraídos da madeira durante o período de envelhecimento ou adicionados na preparação das bebidas (RIZZON et al., 1992).

A aguardente de jabuticaba obteve para extrato seco o valor de 0,11 g.L. $\mathrm{L}^{-1}$ que está dentro da faixa de 0,024 g.L. ${ }^{-1}$ a 0,820 g.L $\mathrm{L}^{-1}$, encontrada para produtos em 24 horas de maturação (MARTÍNEZ et al., 1997), mas elevado se comparado ao valor de 0,03 g. $\mathrm{L}^{-1}$ para aguardente de cana não envelhecida monodestilada (BIZELLI; RIBEIRO; NOVAES, 2000).

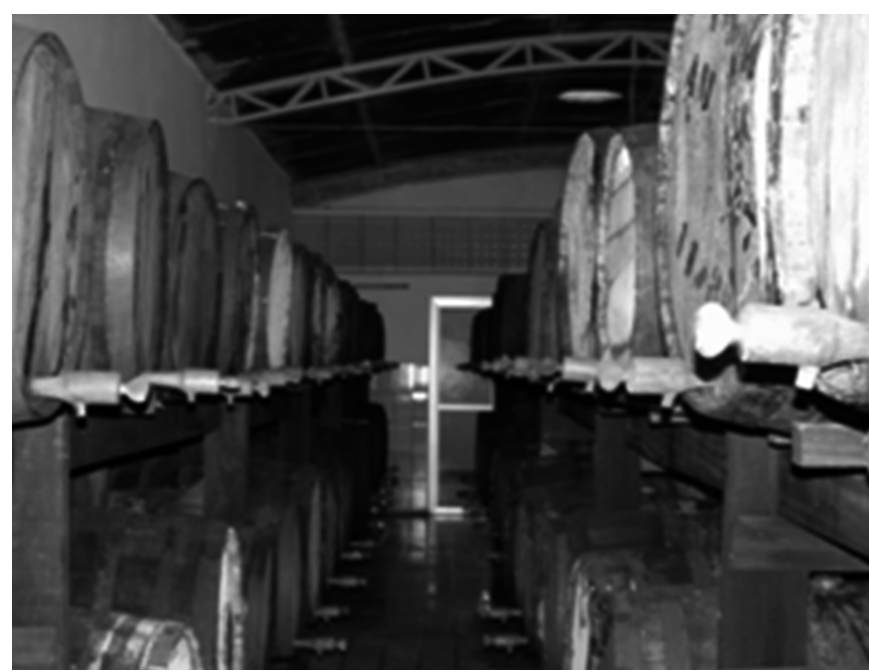

Figura 4. Barris de carvalho.

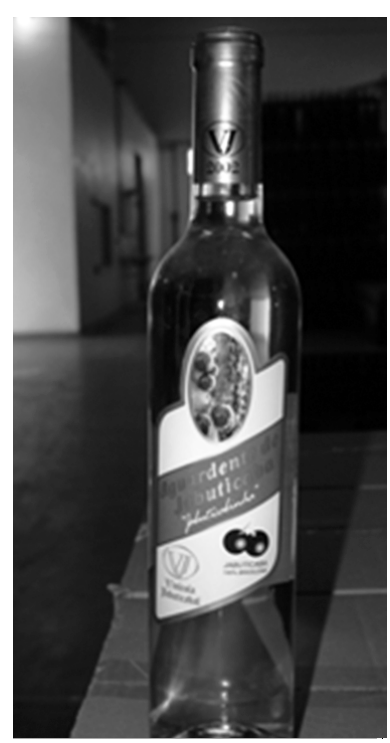

Figura 5. Aguardente de jabuticaba. 
$\mathrm{Na}$ aguardente de jabuticaba analisada, estão ausentes açúcares redutores e sacarose. A legislação brasileira permite valores acima de 6 g.L. $\mathrm{L}^{-1}$, no máximo 30 g.L. ${ }^{-1}$, embora, neste caso, deva ser denominado o produto no rótulo como aguardente adoçada (BRASIL, 2008). Açúcares redutores podem aparecer em aguardentes envelhecidas em barris de carvalho, como consequência da hidrólise da hemicelulose da madeira, mas em quantidades muito pequenas (MARTÍNEZ et al., 1997).

A respeito da acidez total, foi encontrado para a aguardente de jabuticaba o valor de 55,00 mg.100 $\mathrm{mL}^{-1}$, próximo aos valores de 43,9 mg.100 $\mathrm{mL}^{-1}$ para aguardente de cana de destilação simples sem envelhecimento (BIZELLI; RIBEIRO; NOVAES, 2000), para cachaça de abacaxi, 43,2 mg.100 mL $\mathrm{m}^{-1}$ (SILVA JÚNIOR et al., 2006) e de aguardente de banana prata integral, 56,10 mg.100 $\mathrm{mL}^{-1}$ (SILVA et al., 2004), mas diferenciando dos valores para aguardente de laranja de 29,7 mg.100 mL $\mathrm{mL}^{-1}$ e de uva, 71,2 mg.100 mL $\mathrm{mL}^{-1}$ (CLETO; MUTTON, 2004). Boza e Horii (1998) afirmam que a acidez pode ser reduzida através de bidestilação, fato confirmado por Bizelli, Ribeiro e Novaes (2000) que obtiveram, em seu estudo para acidez total, $43,95 \mathrm{mg} .100 \mathrm{~mL}^{-1}$ para aguardente monodestilada e $17,95 \mathrm{mg} .100 \mathrm{~mL}^{-1}$ para aguardente bidestilada.

Uma alta acidez volátil é indicativa de contaminação microbiana advinda da falta de assepsia no processo e do não recolhimento da fração ideal do destilado (VARGAS; GLORIA, 1995). É permitido um máximo de $100 \mathrm{mg} .100 \mathrm{~mL}^{-1}$ para acidez volátil segundo a legislação brasileira (BRASIL, 2008). Para aguardente de jabuticaba, o valor foi de $30 \mathrm{mg} .100 \mathrm{~mL}^{-1}$, compatível com os valores encontrados de 33,195 mg. $100 \mathrm{~mL}^{-1}$ para cachaça de abacaxi (SILVA JÚNIOR et al., 2006), de $24,41 \mathrm{mg} .100 \mathrm{~mL}^{-1}$ para polpa de banana prata (SILVA et al., 2004) e de 30,22 mg. $100 \mathrm{~mL}^{-1}$ para aguardente de cana armazenada em barril de carvalho, porém em um tempo maior (30 meses) que a aguardente de jabuticaba (PARAZZI et al., 2008). Valores de 0,48 a $52,8 \mathrm{mg} .100 \mathrm{~mL}^{-1}$ foram relatados para aguardente de cana de acordo com seu tempo de maceração (MARTÍNEZ et al., 1997).

A acidez fixa se determina pela diferença entre acidez total e a volátil. Seu valor para a aguardente de jabuticaba foi de $25,00 \mathrm{mg} .100 \mathrm{~mL}^{-1}$, não podendo ser comparado ao encontrado para aguardente de destilação simples sem envelhecimento de 1,35 mg.100 ml-1 (BIZELLI; RIBEIRO; NOVAES, 2000), e ao encontrado para aguardente de casca de banana prata de 10,84 mg.100 mL $\mathrm{mL}^{-1}$ (SILVA et al., 2004), assemelhando-se a da cachaça de abacaxi de 27,6 mg.100 mL $\mathrm{mL}^{-1}$ (SILVA JÚNIOR et al., 2006). Em estudo realizado por Martínez et al. (1997) em aguardentes após 24 horas de maturação, a acidez fixa oscilou entre 0,72 e $8,16 \mathrm{mg} .100 \mathrm{~mL}^{-1}$. A acidez fixa tem comportamento semelhante à acidez total, pois também aumenta com o tempo de permanência da aguardente nos barris, estando relacionada com a extração de taninos e compostos de caráter ácido presentes na madeira (MARTÍNEZ et al., 1997).

$\mathrm{O}$ pH para aguardente de jabuticaba foi de 2,83, inferior aos valores das aguardentes de cana aromatizadas com casca de laranja, de 3,9, e com casca de tangerina, 4,3 (ALVAREZ et al., 2004), e de 4,41 para aguardente de cana armazenada em barril de carvalho por 6 meses (PARAZZI et al., 2008).
As cinzas não correspondem necessariamente à soma das substâncias minerais presentes, por causa das perdas por volatilização ou mesmo pela interação entre os componentes durante a realização da análise (CECCHI, 1999). Alguns elementos que compõem as cinzas estão presentes na madeira, portanto seu teor está diretamente relacionado com o período de envelhecimento (RIZZON et al., 1992). O valor encontrado para cinzas na aguardente de jabuticaba foi de $0,005 \%$.

Foram realizadas análises de minerais obtendo-se: para cálcio, 2,20 mg.dL ${ }^{-1}$; para ferro, 0,05 mg.dL ${ }^{-1}$; para magnésio, $0,50 \mathrm{mg} \cdot \mathrm{dL}^{-1}$; e para fosfato, $0,20 \mathrm{mg} \cdot \mathrm{dL}^{-1}$. Constatou-se que o álcool é um interferente na realização analítica, portanto a amostra deve ser desalcoolizada para identificar estes componentes. Não foram encontrados na literatura dados para referência de minerais em aguardente. Entretanto, para conhaques, afirma-se que é elevado um teor de cálcio acima de $0,8 \mathrm{mg} \cdot \mathrm{dL}^{-1}$, podendo causar precipitações. Para o teor de ferro, considera-se baixo um valor inferior a $620 \mathrm{mg} \cdot \mathrm{dL}^{-1}$ (RIZZON et al., 1992).

Os alambiques são, em sua maioria, construídos em cobre por ser um metal maleável, bom condutor de calor, resistente ao desgaste físico. O cobre reduz a acidez e os níveis de aldeídos e compostos sulfurosos que podem conferir sabor e odores estranhos. Entretanto, altos níveis de cobre na bebida causam lesões em vasos capilares, fígado e rins, devido à formação do azinhavre, sal básico de cobre, que é arrastado pelos vapores, contaminando o destilado. Para evitar altos níveis, recomendase a limpeza apropriada de alambiques e/ou tratamento da aguardente com carvão ativado. Neste caso, deve-se observar a concentração e o tempo de contato para não afetar o aroma e o sabor da aguardente, pois pode ocorrer uma redução da acidez volátil, ésteres e álcoois superiores. Outro material adsorvente que pode ser utilizado para remover o cobre é a zeólita. Ressalta-se que o uso de cobre nas partes ascendentes não traz alterações, pois a referida contaminação ocorre na parte descendente (CANTÃO, 2006; LIMA et al., 2006; VARGAS; GLORIA, 1995).

O tratamento de aguardente com carbonato de cálcio ou magnésio também se mostra eficiente sem alterar sensorialmente a bebida, estes compostos atuam como trocadores catiônicos e devem ser utilizados durante a destilação ou antes do envelhecimento, para se evitar os efeitos causados por compostos orgânicos extraídos da madeira (NEVES et al., 2007). Outros meios para se diminuir o teor de cobre é o processo de envelhecimento que, segundo Cavalheiro et al. (2003), pode reduzir até $70 \%$. Já Boza e Horii (2000) constataram que o teor de cobre está relacionado à acidez e que ambos podem ser reduzidos com a eficiente retirada da fração cauda.

Para a aguardente de jabuticaba, o teor de cobre foi de $0,7 \mathrm{mg} . \mathrm{L}^{-1}$, situando-se abaixo dos valores encontrados para aguardente de polpa de banana prata de $1,7 \mathrm{mg} . \mathrm{L}^{-1}$ e de casca de banana, de 1,3 mg.L $\mathrm{L}^{-1}$ (SILVA et al., 2004), cachaça irradiada de 1,31 mg. L $^{-1}$ (MIRANDA; HORII; ALCARDE, 2006), assim como o valor máximo estipulado pela legislação de 5,00 mg.100 mL $\mathrm{mL}^{-1}$ (BRASIL, 2008). 
Para dióxido de enxofre livre em aguardente de jabuticaba, o valor foi de $3,17 \mathrm{mg} . \mathrm{L}^{-1}$ e para o dióxido de enxofre total, $5,28 \mathrm{mg} . \mathrm{L}^{-1}$. Este parâmetro de qualidade não é rotina para aguardentes, pois geralmente o dióxido de enxofre é utilizado na produção de vinhos, sendo este aditivo adicionado antes da fermentação para seleção de microrganismos. Como a aguardente de jabuticaba é um subproduto do fermentado de jabuticaba e na preparação deste é acrescentado o dióxido de enxofre, justifica-se a análise. Para vinhos, a Portaria n ${ }^{\circ} 229$ de 25/10/1988 (BRASIL, 1988) estabelece um máximo de 350 mg.L-1 para dióxido de enxofre total. Quando a amostra apresenta altos conteúdos de dióxido de enxofre, é necessário fazer correção da acidez volátil, pois este composto é parcialmente destilado com o ácido acético.

O teor de taninos determinado na aguardente de jabuticaba foi de $0,03 \mathrm{~g} . \mathrm{L}^{-1}$. Este valor corresponde aos taninos solúveis em água provenientes da prensagem da casca da jabuticaba na preparação da bebida. Existem taninos na casca e nas sementes de frutas como a uva, podendo estar presentes em sucos e vinhos. Nos vinhos preparados com bagaço, pode ocorrer a formação de compostos de ferro e tanino, escurecendo a bebida. Mostos, nos quais a uva passa por prensagem, contém de 0 a 0,2 g.L. $\mathrm{L}^{-1}$, podendo aumentar até 1 g. $\mathrm{L}^{-1}$, se a prensagem não for imediatamente após a maceração. Já em vinhos tintos fermentados, pode-se encontrar um conteúdo de 1 a 2,5 g.L. $\mathrm{L}^{-1}$ (VOGT, 1972). O valor inferior encontrado para aguardente de jabuticaba deve-se ao fato de se ter projetado um esmagador e uma prensa que evitam o esmagamento e a trituração das sementes, reduzindo a extração dos compostos fenólicos.

O processo de irradiação tanto do barril quanto da própria cachaça influencia na extração de compostos fenólicos como demonstram Miranda, Horii e Alcarde (2006), que obtiveram o valor de $87,04 \mathrm{mg} .100 \mathrm{~mL}^{-1}$. Além do teor de taninos, a irradiação também altera a cor e a concentração de aldeídos.

O furfural, segundo Boza e Oetterer (1999), contribui para o sabor ardente, podendo ser oriundo da madeira ou da destilação, como produto da desidratação ou degradação térmica do açúcar durante o aquecimento prolongado em alambique. Masson et al. (2007) relatam que, no caso da aguardente de cana, o teor de furfural também pode estar relacionado à queima da palha da cana, processo utilizado para facilitar a colheita, pois, com o calor, gera-se o furfural que é transferido para a aguardente. $\mathrm{Na}$ aguardente de jabuticaba não foi detectado furfural.

Referente aos ésteres, que são produtos de reações químicas ocorridas durante a fermentação, o valor máximo para aguardente de frutas é de $250 \mathrm{mg} .100 \mathrm{~mL}^{-1}$, segundo a legislação brasileira (BRASIL, 2008). Valor acima foi encontrado para aguardente de jabuticaba, de $357 \mathrm{mg} .100 \mathrm{~mL}^{-1}$. Menores valores foram relatados para amostras de aguardente de cana provenientes da destilação simples de $20 \mathrm{mg} .100 \mathrm{~mL}^{-1}$ (BIZELLI; RIBEIRO; NOVAES, 2000). Já Boza e Oetterer (1999) encontraram valor de $171,28 \mathrm{mg} .100 \mathrm{~mL}^{-1}$ e Martínez et al. (1997) obtiveram valores que oscilaram entre 4,6 e 19,4 mg. $100 \mathrm{~mL}^{-1}$. Próximos aos da aguardente de melão de 4,08 a $15,4 \mathrm{mg} .100 \mathrm{~mL}^{-1}$ (HERNÁNDEZ-GÓMEZ; ÚBEDA; BRIONES, 2003) e das aguardentes obtidas com banana prata integral e casca de banana, de 21,40 e $17,33 \mathrm{mg} .100 \mathrm{~mL}^{-1}$, respectivamente
(SILVA et al., 2004). Concentrações elevadas de ésteres podem diminuir a qualidade do destilado, conferindo-lhe um sabor enjoativo e desagradável (LIMA et al., 2006).

O teor de ésteres pode ser controlado através do uso de substratos adequados, controle do tempo de fermentação, recolhimento da fração ideal do destilado (VARGAS; GLORIA, 1995). O valor elevado de ésteres para aguardente de jabuticaba possivelmente foi em razão de uma falha no recolhimento do primeiro destilado (cabeça) que é constituído de altas concentrações de acetato de etila (BOZA; HORII, 1999). Também pode ter influenciado o tipo de destilação praticada, já que na destilação lenta existe uma grande quantidade de ésteres, enquanto que na rápida esta diminui (AQUARONE et al., 2001; BOZA; HORII, 1999). A presença de células de leveduras no fermentado, durante a destilação, também pode ter afetado a concentração de ácidos graxos e ésteres no destilado, pois os ácidos e ésteres de maior peso molecular estão intimamente ligados a células de levedura, enquanto aqueles de menor peso tendem a passar para o meio de fermentação (BOZA; HORII, 1999).

$\mathrm{O}$ valor encontrado para aguardente de jabuticaba para aldeídos foi de $13,60 \mathrm{mg} .100 \mathrm{~mL}^{-1} \mathrm{O}$ máximo permitido pela legislação brasileira é de $30 \mathrm{mg} .100 \mathrm{~mL}^{-1}$ (BRASIL, 2008). Valores próximos foram encontrados em aguardentes de cana bidestilada de $15,80 \mathrm{mg} .100 \mathrm{~mL}^{-1}$ e de destilação simples,

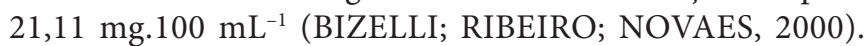
Valores bem elevados foram encontrados para aguardente de uva e laranja, de 58,6 mg.100 mL $\mathrm{mL}^{-1}$ e $86,2 \mathrm{mg} .100 \mathrm{~mL}^{-1}$, respectivamente (CLETO; MUTTON, 2004) e também para cachaça irradiada de 42,07 mg.100 mL ${ }^{-1}$ (MIRANDA; HORII; ALCARDE, 2006).

O aldeído é um composto que diminui a qualidade da cachaça e, quando ingerido, interfere no sistema nervoso central, portanto é importante quantificá-lo, sendo que sua concentração deverá ser o mínimo possível (VILELA et al., 2007). Seu principal representante é o acetaldeído A concentração de acetaldeído está relacionada aos processos de oxidação que sofre o etanol, portanto a diminuição do oxigênio dissolvido neste tipo de bebida acarreta menor produção deste composto (MARTÍNEZ et al., 1997). Em concentrações elevadas, indicam que o mosto foi arejado ou recebeu doses elevadas de sulfitação antes da fermentação alcoólica (ASQUIERI et al., 2004b).

Segundo o Decreto ${ }^{\circ} 2314$ (BRASIL, 1997), entende-se como coeficiente de congêneres ou componentes secundários não álcool, a soma de acidez volátil, expressa em ácido acético, aldeídos, expresso em acetaldeído, ésteres, expresso em acetato de etila, álcoois superiores, expressos pelo somatório deles, e furfural, todos expressos em miligramas por cem mililitros de álcool anidro. Pelo fato de apresentar um alto teor de ésteres, a aguardente de jabuticaba também obteve um alto teor de coeficiente de congêneres $\left(659,67 \mathrm{mg} .100 \mathrm{~mL}^{-1}\right)$, ultrapassando o valor máximo permitido pela legislação para aguardente de frutas de $650,00 \mathrm{mg} .100 \mathrm{~mL}^{-1}$ (BRASIL, 2008) e também o encontrado para cachaça irradiada de $583,02 \mathrm{mg} .100 \mathrm{~mL}^{-1}$ (MIRANDA; HORII; ALCARDE, 2006). 
Os álcoois superiores apresentam-se em quantidades mínimas, como o isobutílico, amílico, propílico e isopropílico. Têm ação solvente sobre outras substâncias aromáticas interferindo nos graus de volatilidade destas. São formados a partir da transaminação de certos aminoácidos ou da desaminação e descarboxilação de outros (BOZA; HORII, 1999; RIZZON et al., 1992).

A aguardente de jabuticaba apresentou um teor de álcoois superiores de 259,07 mg.100 mL valor de $320,1 \mathrm{mg} .100 \mathrm{~mL}^{-1}$ para aguardente de cana com mesmo período de armazenamento em barris de carvalho (PARAZZI et al., 2008), de aguardente de casca de banana,

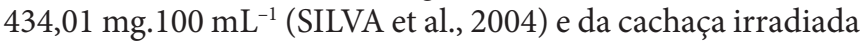
de 426,58 mg.100 mL mL $^{-1}$ (MIRANDA; HORII; ALCARDE, 2006), como também do valor estipulado pela legislação para aguardente de frutas de $360,00 \mathrm{mg} .100 \mathrm{~mL}^{-1}$ (BRASIL, 2008).

Alguns constituintes dos álcoois superiores são apresentados na Tabela 2.

Em relação aos compostos voláteis, o teor de álcool n-propílico (45,97 mg.100 mL $\left.{ }^{-1}\right)$ e n-butílico $\left(0,70 \mathrm{mg} \cdot 100 \mathrm{~mL}^{-1}\right)$ da aguardente de jabuticaba apresentaram-se acima dos valores relatados para aguardente de cana monodestilada de 27,82 e $0,51 \mathrm{mg} .100 \mathrm{~mL}^{-1}$, respectivamente (BIZELLI; RIBEIRO; NOVAES, 2000), e também dos relatados por Alvarez et al. (2004) para aguardentes de cana aromatizadas com casca de laranja e com casca de tangerina, que obtiveram respectivamente 4,99 e 4,62 mg. $100 \mathrm{~mL}^{-1}$ para álcool n-propílico e $1,00 \mathrm{mg} \cdot 100 \mathrm{ml}^{-1}$ para o n-butílico.

Entretanto, os valores para álcool iso-butílico (57,10 mg.100 mL $\left.\mathrm{mL}^{-1}\right)$ e iso-amílico (156,00 mg.100 mL $\left.\mathrm{mL}^{-1}\right)$ foram menores do que os valores encontrados para aguardente monodestilada de $81,17 \mathrm{mg} .100 \mathrm{~mL}^{-1}$ (iso-butílico) e

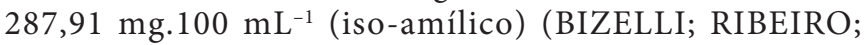
NOVAES, 2000) e da aguardente de banana nanica cujos valores foram: $152,88 \mathrm{mg} .100 \mathrm{~mL}^{-1}$ para álcool iso-butílico e de $406,67 \mathrm{mg} .100 \mathrm{~mL}^{-1}$ para álcool iso-amílico (GUIMARÃES FILHO, 2003). Em estudo realizado por Parazzi et al. (2008) com aguardente de cana armazenada em barris de carvalho por 6 meses, similar ao tratamento da aguardente de jabuticaba, os valores para o álcool n-butílico (1,03 mg. $\left.100 \mathrm{~mL}^{-1}\right)$, n-propílico $\left(66,86 \mathrm{mg} \cdot 100 \mathrm{~mL}^{-1}\right)$ e iso-amílico $\left(195,1 \mathrm{mg} \cdot 100 \mathrm{~mL}^{-1}\right)$ foram mais elevados, apenas o teor de álcool iso-butílico (57,81 mg.100 mL $\left.\mathrm{mL}^{-1}\right)$ foi semelhante.

O metanol ocorre naturalmente nas bebidas alcoólicas, como produto secundário no processo de fermentação, em quantidades pequenas que não oferecem risco toxicológico (ZENEBON et al., 1996). Nos destilados alcoólicos de frutas,

Tabela 2. Compostos voláteis da aguardente de jabuticaba.

\begin{tabular}{lc}
\hline \multicolumn{1}{c}{ Compostos } & Valores médios \\
\hline Álcool sec-butílico (mg.100 mL-1) & 1,67 \\
Álcool n-butílico (mg.100 mL $\left.\mathrm{mL}^{-1}\right)$ & 0,70 \\
Álcool n-propílico (mg.100 mL $\left.\mathrm{mL}^{-1}\right)$ & 45,97 \\
Álcool iso-butílico (mg.100 mL & 57,10 \\
Álcool iso-amílico (mg.100 mL & 156,00 \\
\hline
\end{tabular}

principalmente aqueles que passam por prensagem do bagaço, o teor encontrado é maior, porque substâncias pécticas contidas nas diferentes partes da fruta sofrem degradação pela ação de enzimas, principalmente as pectina-metilestereases. Como exemplo, tem-se a grappa, bebida destilada produzida a partir da fermentação de bagaço de uva e que apresenta teor de metanol variando de 38 a $138 \mathrm{mg} .100 \mathrm{~mL}^{-1}$ (HONG; WOODAMS, 2008). A concentração de metanol está diretamente relacionada à natureza e à quantidade das substâncias pécticas na fruta e à concentração das enzimas que estão em contato com o substrato (DIÉGUEZ; GIL; FERNÁNDEZ, 2000).

A aguardente de jabuticaba obteve $4,30 \mathrm{mg} .100 \mathrm{~mL}^{-1}$ de metanol sendo inferior ao valor máximo estipulado pela legislação de $20 \mathrm{mg} .100 \mathrm{~mL}^{-1}$ (BRASIL, 2008) e ao relatado por Bizelli, Ribeiro e Novaes (2000) para aguardente de cana monodestilada, $17,36 \mathrm{mg} .100 \mathrm{~L}^{-1}$. No entanto, Parazzi et al. (2008) encontraram um teor de metanol menor $\left(3,84 \mathrm{mg} .100 \mathrm{~mL}^{-1}\right)$ para aguardente de cana armazenada em barril de carvalho por 6 meses, assim como Hernández-Gómez et al. (2005) para aguardente de polpa de melão de 3,06 mg.100 $\mathrm{mL}^{-1}$. Já aguardentes de cana aromatizadas com casca de laranja e com casca de tangerina obtiveram respectivamente 5,15 e 4,02 mg. $100 \mathrm{~mL}^{-1}$ (ALVAREZ et al., 2004) e para cachaça irradiada o teor de metanol foi de $6,84 \mathrm{mg} .100 \mathrm{~mL}^{-1}$ (MIRANDA; HORII; ALCARDE, 2006).

\section{Conclusão}

A casca e a borra, subprodutos da fabricação do fermentado de jabuticaba são matérias-primas de grande potencial para fabricação de aguardente de jabuticaba. A aguardente de jabuticaba analisada neste experimento apresentou valores compatíveis aos da aguardente de frutas no que se refere à sua composição físico-química, com exceção do valor elevado de ésteres. Em um país que é mundialmente conhecido como produtor de aguardente de cana, o produto estudado é uma alternativa para produtores rurais que cultivam a jabuticaba, evitando perdas pós-colheita consideráveis durante a safra, que é curta (4 meses). Estudos mais abrangentes para esta bebida devem ser realizados, já que é um produto novo no mercado nacional.

\section{Referências bibliográficas}

AlvarengA, L. M.; MAIA, A. B. R. A.; OliveirA, E. S. Processamento, avaliação química e sensorial de aguardente de manga (Mangifera indica L.). In: CONGRESSO BRASILEIRO DE CIÊNCIA E TECNOLOGIA DE ALIMENTOS, 20, 2006, Curitiba. Anais... Curitiba: SBCTA, 2006. 1 CD-ROM.

ALVAREZ, M. J. M. et al. Cambios fisicoquímicos en dos aguardientes dulces aromatizados con cáscaras de mandarina y naranja. Revista de la Facultad de Agronomía, v. 21, p. 285-296, 2004.

AMERINE, M. A.; OUGH, C. S. Analisis de vinos y mostos. Zaragoza: Editorial Acribia, 1976.

ANDERSEN, O. As frutas silvestres brasileiras. São Paulo: Globo, 1989.

ANDRADE, J. S.; PANTOJA, L.; MAEDA, R. N. Melhoria do rendimento e do processo de obtenção da bebida alcoólica de 
pupunha (Bactris gasipaes Kunth). Ciência e Tecnologia de Alimentos, v. 23, p. 34-38, 2003.

AQUARONE, E. et al. Biotecnologia Industrial: biotecnologia na produção de alimentos. São Paulo: Edgard Blucher, 2001. v. 4.

ASQUIERI, E. R. et al. Fabricación de vino blanco y tinto de jabuticaba (Myrciaria jaboticaba Berg) utilizando la pulpa y la cáscara respectivamente. Alimentaria, n. 355, p. 97-109, 2004a.

ASQUIERI, E. R. et al. Vino de jabuticaba (Myrciaria cauliflora Berg): estudio de las características físico-químicas y sensoriales de los vinos tinto seco y dulce, fabricados com la fruta integral. Alimentaria, n. 355, p. 111-122, 2004 b.

BIZELLI, L. C.; RIBEIRO, C. A. F.; NOVAES, F. V. Dupla destilação da aguardente de cana: teores de acidez total e de cobre. Scientia Agrícola, v. 57, n. 4, p. 623-627, 2000.

BOZA, Y.; HORII, J. Influência da destilação sobre a composição e qualidade sensorial da aguardente de cana-de-açúcar. Ciência e Tecnologia de Alimentos, v. 18, n. 4, p. 391-396, 1998.

BOZA, Y.; HORII, J. A destilação na obtenção de aguardente de canade-açúcar. Boletim SBCTA, v. 33, n. 1, p. 98-105, 1999.

BOZA, Y.; OETTERER, M. Envelhecimento de aguardente de cana. Boletim SBCTA, v. 33, n. 1, p. 8-15, 1999.

BOZA, Y.; HORII, J. Influência do grau alcoólico e da acidez do destilado sobre o teor de cobre na aguardente. Ciência e Tecnologia de Alimentos, v. 20, n. 3, p. 279-284, 2000.

BRASIL. Ministério da Agricultura, Pecuária e Abastecimento. Portaria $n^{\circ}$ 229, de 25 de outubro de 1988: complementação de padrões de identidade e qualidade de vinho. Brasília, DF, 1988. Disponível em: $<\mathrm{http} / /$ www.agricultura.gov.br>. Acesso em: 04 dez. 2005.

BRASIL. Ministério da Agricultura, Pecuária e Abastecimento. Decreto $n^{\circ}$ 2314, de 04 de setembro de 1997: dispõe sobre a padronização, a classificação, o registro, a inspeção, a produção e a fiscalização de bebidas. Brasília, DF, 1997. Disponível em: <http//www.agricultura. gov.br>. Acesso em: 04 dez. 2005.

BRASIL. Ministério da Agricultura, Pecuária e Abastecimento. Instrução normativa $\mathbf{n}^{\circ} \mathbf{2 4}$, de 08 de setembro de 2005: manual operacional de bebidas e vinagres. Brasília, DF, 2005. Disponível em: <www.agricultura.gov.br>. Acesso em: 10 set. 2008.

BRASIL. Ministério da Agricultura, Pecuária e Abastecimento. Portaria $n^{\circ}$ 65, de 23 de abril de 2008: regulamento técnico para a fixação dos padrões de identidade e qualidade para aguardente de fruta. Brasília, DF, 2008. Disponível em: <www.agricultura.gov.br>. Acesso em: 10 set. 2008.

BRIONES, A. I.; HERNÁNDEZ-GÓMEZ, L. F.; UBEDA, J. F. Elaboración de aguardiente de melón. Alimentación, equipos y tecnología, n. 171, p. 47-52, 2002.

BRUNINI, M. A. et al. Influência de embalagens e temperatura no armazenamento de jabuticabas (Myrciaria jabuticaba (Vell) Berg) cv 'Sabará. Ciência e Tecnologia de Alimentos, v. 24, n. 3, p. 378383, 2004.

CANECHIO FILHO, V. Instituto Campineiro de Ensino Agrícola. São Paulo: ICEA, 1972.

CANTÃO, F. O. Análises físico-químicas e avaliação da presença do cobre em aguardente de cana por aluminossilicatos. 2006. 62 p. Dissertação (Mestrado em Agroquímica e Agrobioquímica) Faculdade de Agronomia, Universidade Federal de Lavras - UFLA, Lavras, 2006.

CAVALHEIRO, S. F. L. et al. Influência do envelhecimento no teor de cobre em cachaças. Boletim do Centro de Pesquisa e Processamento de Alimentos, v. 21, n. 1, p. 99-108, 2003.
CECCHI, H. M. Fundamentos teóricos e práticos em análise de alimentos. São Paulo: Editora da Unicamp, 1999.

CLETO, F. V. G.; MUTTON, M. J. R. Rendimento e composição das aguardentes de cana, laranja e uva com utilização de lecitina no processo fermentativo. Ciência e Agrotecnologia, v. 28, n. 3, p. 577-584, 2004.

CORAZZA, M. L.; RODRIGUES, D. G.; NOZAKI, J. Preparação e caracterização do vinho de laranja. Química Nova, v. 24, p. 449-452, 2001.

DIAS, D. R.; SCHWAN, R. F.; LIMA, L. C. O. Metodologia para elaboração do fermentado de cajá (Spondias mombin L.). Ciência e Tecnologia de Alimentos, v. 23, n.3, p. 342-350, 2003.

DIÉQUEZ, S. M. C.; GIL, M. L.; FERNÁNDEZ, E. Influencia del nivel de prensado y del estado de conservacion del bagazo en el contenido en metanol, acetato de etilo, 2-butanol y alcohol alilico de aguardientes de orujo, Alimentaria, n. 316, p. 133-138, 2000.

GUIMARÃES FILHO, O. Avaliação da produção artesanal da aguardente de banana utilizando Saccharomyces cerevisiae CA- 1174. 2003. 82 p. Dissertação (Dotorado em Ciência dos Alimentos) - Faculdade de Engenharia de Alimentos, Universidade Federal de Lavras - UFLA, Lavras, 2003.

HANG, Y. D.; WOODAMS, E. E. Methanol content of grappa made from New York grape pomace. Bioresource Technology, n. 99, p. 3923- 3925, 2008.

HERNÁNDEZ-GÓMEZ, L. F.; ÚBEDA, J.; BRIONES, A. Melon fruit distillates: comparison of different distillation methods. Food Chemistry, v. 82, p. 539-543, 2003.

HERNÁNDEZ-GÓMEZ, L. F. et al. Comparative production of different melon distillates: chemical and sensory analyses. Food Chemistry, n. 90, p. 115-125, 2005.

INSTITUTO ADOLFO LUTZ - IAL. Normas analíticas do Instituto Adolfo Lutz: métodos químicos e físicos para análise de alimentos. 3. ed. São Paulo: O Instituto, 1985.

LABTEST. Sistema para diagnóstico. Belo Horizonte, 1995.

LIMA, A. J. B. et al. Emprego do carvão ativado para remoção de cobre em cachaça. Química Nova, v. 29, p. 247-250, 2006.

MARTÍNEZ, R. G. et al. Evolucion de los parâmetros físico-quimicos em aguardientes macerados com madera de roble: influencia del tiempo de maceración. Alimentaria, n. 284, p. 111-117, 1997.

MASSON, J. et al. Parâmetros físico-químicos e cromatográficos em aguardentes de cana queimada e não queimada. Ciência Agrotécnica, v. 31, n. 6, p. 1805- 1810, 2007.

MILLER, G. L. Use of 3-5 dinitrosalicylic acid for determination of reducing sugar. Analytical Chemistry, v. 31, n. 2, p. 426-428, 1959

MIRANDA, M. B.; HORII, J.; ALCARDE, A. R. Estudo do efeito da irradiação gamma $\left({ }^{60} \mathrm{CO}\right)$ na qualidade da cachaça e no tonel de envelhecimento. Ciência e Tecnologia de Alimentos, v. 26, n. 4, p. 772-778, 2006.

MORI, F. A. Utilização de eucaliptos e de madeiras nativas no armazenamento da aguardente de cana-de-açúcar. Ciência e Tecnologia de Alimentos, v. 23, n. 3, p. 394-400, 2003.

MUNHOZ, C. L. et al. Produção e análise de aceitação de cachaça de mexerica por teste afetivo. In: CONGRESSO BRASILEIRO DE CIÊNCIA E TECNOLOGIA DE ALIMENTOS, 20, 2006, Curitiba. Anais... Curitiba: SBCTA, 2006. 1 CD-ROM.

MUNIZ, C. R. et al. Bebidas fermentadas a partir de frutos tropicais. Boletim do Centro de Pesquisa e Processamento de Alimentos, v. 20 , n. 2, p. 309-322, 2002. 
NASCIMENTO, R. F. et al. Influência do material do alambique na composição química das aguardentes de cana-de-açúcar. Química Nova, v. 21, n. 6, p. 735-739, 1998.

NEVES, E. A. et al. Simple and efficient elimination of copper (II) in sugar-cane spirits. Food Chemistry, n. 101, p. 33-36, 2007.

PARAZZI, C. et al. Avaliação e caracterização dos principais compostos químicos da aguardente de cana-de-açúcar envelhecida em tonéis de carvalho (Quercus sp.). Ciência e Tecnologia de Alimentos, v. 28, n. 1, p. 193-199, 2008.

RIZZON, L. A. et al. Características analíticas dos conhaques da microrregião homogênea vinicultora de Caxias do Sul. Ciência e Tecnologia de Alimentos, v. 12, n. 1, p. 43-51, 1992.

SILVA JÚNIOR, Z. P. et al. Características físico-químicas da cachaça de abacaxi. In: CONGRESSO BRASILEIRO DE CIÊNCIA E TECNOLOGIA DE AlimENTOS, 20, 2006, Curitiba. Anais... Curitiba: SBCTA, 2006. 1 CD-ROM.

SILVA, R. N. et al. Comparação de métodos para a determinação de açúcares redutores e totais em mel. Ciência e Tecnologia de Alimentos, v. 23, n. 3, p. 337-341, 2003.

SILVA, M. B. L. et al. Hidrólise enzimática da polpa e qualidade físico-química de aguardente de banana refugo. In: CONGRESSO
BRASILEIRO DE CIÊNCIA E TECNOLOGIA DE ALIMENTOS, 19, 2004, Recife. Anais... Recife: SBCTA, 2004. 1 CD-ROM.

TORRES NETO, A. B. et al. Cinética e caracterização físico-química do fermentado do pseudofruto do caju (Anacardium occidentale L.). Química Nova, v. 29, n. 3, p. 489-492, 2006.

VARGAS, E. A.; GLORIA, M. B. Qualidade da aguardente de cana (Saccharum officinarum, L.) produzida, comercializada e/ou engarrafada no Estado de Minas Gerais. Ciência e Tecnologia de Alimentos, v. 15, n. 1, p. 43-46, 1995.

VILELA, G. G.; BACILA, M.; TASTALDI, H. Técnicas e experimentos de bioquímica. Rio de Janeiro: Guanabara Koogan, 1973.

VILELA, F. J. et al. Determinação das composições físico-químicas de cachaças do sul de Minas Gerais e de suas misturas. Ciência Agrotécnica, v. 31, n. 4, p. 1089- 1094, 2007.

VOGT, E. La fabricacion de vinos. Zaragoza: Editorial Acribia, 1972.

ZENEBON, O. et al. Metanol - avaliação da ocorrência de intoxicações causadas pela ingestão de bebidas alcoólicas no estado de São Paulo. Boletim SBCTA, v. 30, n. 1, p. 71-74, 1996. 